ORIGINAL PROF-2215

\title{
INFLUENCE OF TOURNIQUET APPLICATION;
}

\section{ON SELECTED CHEMICAL ANALYTES}

\section{Dr. Farheen Aslam, Dr. Asma Shaukat, Dr. Zakir Ali, Dr. Tariq M Arain}

ABSTRACT... Objective: The objective of the study was to determine the mean change in selected chemical analytes with and without application of tourniquet. Data source: Blood samples were collected from all persons irrespective of age and gender visiting pathology laboratory, Quaid-e-Azam Medical College, Bahawalpur. Study design: The study was a Quasi experimental study. Setting: The study was carried out in Pathology Laboratory, Quaid-e-Azam Medical College, Bahawalpur on Selectra XL and Easy lyte. Period: October 2011 to April 2012. Subject and method: Blood samples were taken from both arms of 265 volunteer with one difference that standardized external pressure of $60 \mathrm{~mm} \mathrm{Hg}$ was applied by using a sphygmomanometer for one minute on one arm and on other arm blood sample was collected without application of tourniquet. Results: Samples with tourniquet application showed statistically significant mean increase in serum concentration of protein $(p=0.001)$, cholesterol $(p=0.03)$, calcium $(p=0.007)$ and potassium $(p=0.0001)$. The mean concentration of serum sodium and chloride showed no statistically significant change after one minute of tourniquet application. Conclusions: The tourniquet application of one minute influence certain laboratory parameters, so its use should be kept to a minimum.

Key words: Tourniquet, Venous stasis, Venipuncture, Laboratory, Analytes

Article Citation

Aslam F, Shaukat A, Ali Z, Arain TM. Influence of tourniquet application; on selected chemical analytes. Professional Med J 2013;20(5): 798-803.

\section{INTRODUCTION}

Previously results of analysis were dependent on analytical variation, but nowadays control and standardization of pre-analytical variability is a critical factor for achieving accuracy and precision in laboratory testing because about $32 \%$ to $75 \%$ laboratory errors are made in pre-analytical phase and majority of them are preventable ${ }^{2}$. Venous blood sampling is usually performed using a tourniquet to help locate and define peripheral veins to achieve successful and safe venipuncture. During the last two decades significant improvements in blood sampling technique and equipments e.g. positive patient identification, vacuum tubes for blood sampling, improved needles for phlebotomy and operator safety are made ${ }^{3}$, it is very important to give proper attention and careful supervision to prevent errors during phelabotomy procedure. Tourniquet is widely used for venipuncture by medical and laboratory staff but very few are aware of effect of tourniquet application on laboratory parameters. In addition definitive guide lines regarding how and when to use tourniquet for blood sampling are lacking. Tourniquet application should be minimized because it causes spurious and significant variation of several plasma analytes ${ }^{4}$. For example prolonged venous stasis can cause $7 \%$ increase in prevalence of hypercholesterolemia and thus unnecessary medication can be introduced ${ }^{5}$. Prolonged tourniquet application can lead to local hypoxia and thus acidosis, which can affect potassium measurement ${ }^{6}$. With venous stasis, protein and protein bound constituents can increase upto $15 \%{ }^{7}$. Evidence from study in Verona, Italy ${ }^{4}$ have shown that by measuring plasma concentration of twelve common analytes, collected without and with stasis for one minute have clinically significant elevation for albumin $(44.0 \pm 3.0,45.5 \pm 3.4) \mathrm{mmol} / \mathrm{L}$, calcium $(2.32 \pm 0.13$, $2.36 \pm 0.10) \mathrm{mmol} / \mathrm{L}$, total cholesterol $(5.07 \pm 0.83,5.22 \pm 0.83) \mathrm{mmol} / \mathrm{L}$ and decrease in potassium $(4.21 \pm 0.34,4.09 \pm 0.27) \mathrm{mmol} / \mathrm{L}$.

But other study indicates that blood gases, hematological parameters and serum electrolytes are not affected by application and removal of a tourniquet ${ }^{3}$. So there are conflicting results available regarding the effect of venous stasis by tourniquet application and also there is no such study in this region. Therefore better of the two techniques will be 
used in future.

\section{MATERIALS AND METHODS}

\section{Study Design}

The study was a Quasi experimental study.

\section{Setting}

The study was carried out in Pathology Laboratory, Quaid-e-Azam Medical College, Bahawalpur.

\section{Duration of Study \\ From October 2011 to April 2012.}

\section{Sampling Technique}

Non - probability, consecutive sampling.

\section{SAMPLE COLLECTION}

\section{Inclusion Criteria}

Blood samples were collected from all persons irrespective of age and gender who were willing to give $10 \mathrm{ml}$ of blood, visiting pathology laboratory, Quaid-eAzam Medical College, Bahawalpur.

\section{Exclusion Criteria}

- $\quad$ Persons who refused to give $10 \mathrm{ml}$ of blood.

- Patients of disseminated intravascular coagulation.

- Subjects who were taking steroids and heparin for more than 4 weeks.

- Haemolysed and lipemic sample.

\section{DATA COLLECTION PROCEDURE}

The study was started after taking approval from Ethical committee of Bahawal Victoria Hospital. Written and informed consent was taken from all individuals who met the inclusion criteria. In persons with odd serial number, right arm was used as control and left arm as test arm, whereas, in person with even serial number right arm was used as test arm and left arm as control. The collection of diagnostic blood samples was accomplished by a single expert phlebotomist from median cubital vein in antecubital fossa after being seated for 15 minutes to eliminate the effects of standing posture with one difference that sample was withdrawn from the test arm after application of standardized external pressure of 60 $\mathrm{mm} \mathrm{Hg}$ using a sphygmomanometer for one minute . The needles and vacuum tubes were of same lot.

All blood specimens were drawn by using a $20 \mathrm{G}$ straight sterile needle directly into vacuum tubes with clot activator and acrylic gel separator.

\section{PROCESSING OF BLOOD SAMPLES}

All the tubes were left in upright position for 45 minutes at room temperature to allow complete blood clotting before centrifugation. Serum was separated after centrifugation at $1500 \mathrm{~g}$ for 10 minutes. No blood sample was discarded on the basis of unsatisfactory attempts, difficulty in locating venous access, missing veins and manifest haemolysis.

\section{LABORATORY TESTING}

The concentration of serum sodium, potassium, chloride was estimated on Ion Selective Electrode. Total serum protein and serum cholesterol and calcium were measured on fully automated chemistry analyzer (Selectra XL), by medical technologist with an experience of 5 years, according to the manufacturers specifications and using proprietary reagents. Measurement bias was controlled by calibration of instruments and repeating each test twice within a single analytical session. The results were reported as the mean of paired measurements.

\section{DATA ANALYSIS}

Data was analyzed using statistical package for social sciences (SPSS). Frequency and percentage were calculated for sex while mean and standard deviation were calculated for sodium, potassium, chloride, calcium, protein and cholesterol. The mean change for these analytes was also calculated. T-test was used to compare the means and $P$ value $<0.05$ was taken as significant. Results were presented in the form of 
table.

\begin{tabular}{|l|c|}
\hline \multicolumn{1}{|c|}{ Name of analyte } & Analytical method \\
\hline Total protein & Biurete method \\
\hline Serum cholesterol & $\begin{array}{c}\text { Enzymatic } \\
\text { (cholest. esterase-cholest oxidase) }\end{array}$ \\
\hline Serum calcium & $\begin{array}{c}\text { Direct colorimetric complexometric } \\
\text { (Arsenazo III) }\end{array}$ \\
\hline Serum potassium & ISE \\
\hline Serum sodium & ISE \\
\hline Serum chloride & ISE \\
\hline Table-I. Analytical methods used in the study \\
\hline
\end{tabular}

\section{RESULTS}

In this study, blood samples were taken from 265 subjects and about half of the participants were female of different age group. The results of the study are shown in tables II.

The results of the study showed that the serum potassium, calcium, protein and cholesterol showed statistically significant difference in their mean concentration values while serum sodium and chloride measurements showed insignificant effect. The mean increase in serum potassium was 0.37 $\mathrm{mmol} / \mathrm{L}(p \leq 0.0001)$, calcium showed an increase of $0.05 \mathrm{mmol} / \mathrm{L}(p=0.0064)$, total protein had increase of
about2.7g/L $(p=0.001)$ and there was increase of $0.25 \mathrm{mmol} / \mathrm{L}(p=0.02)$ in the measurement of cholesterol.

\section{DISCUSSION}

The clinical laboratory results are an essential part of the health care delivery. It has been estimated that 60 up to $70 \%$ of medical decisions and procedures, such as drug prescriptions, assessments prior to and in the course of further investigations or dialysis, are strongly dependent upon laboratory data ${ }^{8}$.

The total testing process (TTP) is the total process from the ordering of a test to the interpretation of a test result. The TTP starts and ends with the patient, and can be subdivided into three distinctive phases: the pre-analytical step (before the analysis), the analytical step (the actual analysis) and the post-analytical step(after the analysis), as described in Figure 1.

Errors can occur in every step of the TTP. Of all errors in the TTP, approximately one fourth have consequences for the patient ${ }^{2,9}$. These consequences include a delayed test result or new sample collection which result in increased workload on lab and financial burden on patient, but also life threatening and tragic consequences, such as unnecessary chemotherapy and coma ${ }^{10}$.

\begin{tabular}{|l|c|c|c|c|}
\hline \multicolumn{1}{|c|}{ Analyte } & $\begin{array}{c}\text { Mean concentration } \\
\text { without tourniquet }\end{array}$ & $\begin{array}{c}\text { Mean concentration } \\
\text { with tourniquet }\end{array}$ & $\begin{array}{c}\text { Mean \% } \\
\text { difference }\end{array}$ & p-value \\
\hline Total protein $\mathrm{g} / \mathrm{L}$ & $67.70 \pm 9.67$ & $70.49 \pm 9.73$ & 3.99 & 0.001 \\
\hline Cholesterol mmo// & $4.53 \pm 1.32$ & $4.78 \pm 1.32$ & 5.5 & 0.03 \\
\hline Potassium mmol/L & $4.38 \pm 0.40$ & $4.75 \pm 0.41$ & 8.45 & 0.0001 \\
\hline Calcium mmol/L & $2.22 \pm 0.20$ & $2.27 \pm 0.22$ & 2.25 & 0.007 \\
\hline Sodium mmol/L & $139.31 \pm 3.96$ & $139.07 \pm 3.96$ & 0.17 & 0.49 \\
\hline Chloride $\mathrm{mmol} / \mathrm{L}$ & $102.4 \pm 1.88$ & $102.1 \pm 1.87$ & 0.29 & 0.07 \\
\hline
\end{tabular}


It is evident that the majority of all errors in the TTP are of pre analytical in origin i.e. they occur before the sample arrives in the laboratory ${ }^{2,9}$. Previous reports suggested that about $46-68 \%$ of errors were made in preanalytical phase but advances in automation and instrument technology have improved the quality of test results and it is now stated that up to $93 \%$ of all errors are made in preanalytical phases ${ }^{11}$. Therefore, reduction of preanalytical errors is an important issue for everyone involved in the TTP.

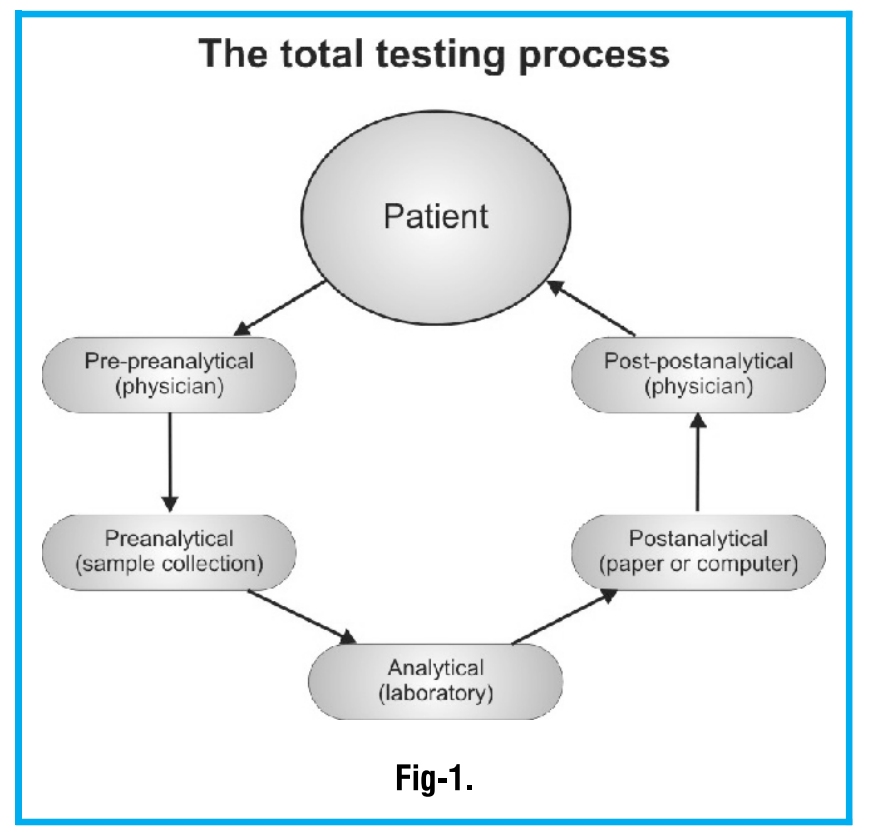

Majority of the preanalytical errors are due to human mistakes $^{12}$ and they are preventable in most of the cases $^{2,12}$. The tourniquet application is an important controllable variable of pre analytical factor that can affect laboratory results. It is usual practice that tourniquet remains in place during blood collection so that continued venous dilation allows rapid sample collection which may result in its prolonged application. This application time is rarely regarded as a potential source of laboratory variability that may be lengthen due to difficult location of vein, selection of proper blood collection system, insertion of needle into the vein and collection of many tubes ${ }^{13}$.

The previous studies conducted on tourniquet application showed conflicting results. The study conducted by Broome et al on electrolytes showed no statistically significant difference when tourniquet was applied for two minutes ${ }^{14}$.

McMullan and his coworkers concluded that calcium and protein measurements showed negligible changes with one minute of tourniquet application ${ }^{15}$.

The results of other studies indicated that the mean change in concentration of analytes were not significant by the use of tourniquet ${ }^{16,17}$. However Renoe et al showed an increase of about $6 \%$ in serum concentration of protein and $2.5 \%$ in calcium after one minute of tourniquet application ${ }^{18}$.

Venous stasis facilitates the exit of water and diffusible ions from the vessels. The resulting hemoconcentration raises the concentration of numerous blood analytes at the punctured site thus influencing the laboratory parameters interpretation.

The results of Lippi et al ${ }^{4}$ were consistent to this study and showed a mean increase in concentration of calcium was $0.04 \mathrm{mmol} / \mathrm{L}$ and mean increase of $0.15 \mathrm{mmol} / \mathrm{L}$ in case of cholesterol with one difference that mean concentration of potassium showed decrease of $0.11 \mathrm{mmol} / \mathrm{L}$.

Another study that was performed by Oliveria $^{19}$ showed mean increase of about $2 \mathrm{~g} / \mathrm{L}$ in case of protein, $0.03 \mathrm{mmol} / \mathrm{L}$ in serum calcium level and $0.3 \mathrm{mmol} / \mathrm{L}$ in serum potassium measurement that were similar to the results of this study. The possible mechanism may be that when vascular environment is subjected to hypoxia and stasis, local acidosis releases potassium from the cells that results in elevated potassium level.

Sonoli ${ }^{20}$ performed study on five routinely advised analytes and showed a mean increase of $0.18 \mathrm{~g} / \mathrm{dl}$ $(p=0.006)$ in protein measurement after one minute 
of tourniqurt use. Differences between the results may be due to difference in technique employed to apply tourniquet, biochemical characteristics of the measuring analyte. The studies were also conducted on different population with different instruments.

\section{CONCLUSIONS}

The venous stasis produced by tourniquet application of one minute can influence laboratory parameters. So every effort should be made to reduce its application time and medical and laboratory staff should be properly educated about the usage of tourniquet.

\section{Copyright@ 20 Apr, 2013.}

\section{REFERENCES}

1. Lippi G, Salvagno GL, Montagnana M, Brocco G, Guidi GC. Venous stasis and routine hematological testing. Clin Lab Haem. 2006;28:332-7.

2. Carraro P, Plebani M. Errors in a stat laboratory: types and frequencies 10 years later. Clin Chem. 2007;53:1338-42.

3. Cengiz M, Ulker P, Herbert J, Baskurt KO. Influence of tourniquet application on venous blood sampling for serum chemistry hematological parameter, leukocyte activation and erythrocyte mechnical properties. Clin Chem Lab Med. 2009;47(6):769-76.

4. Lippi G, Salvagno GL, Montagnana M, Brocco G, Guidi $\mathrm{GC}$. Influence of short term venous stasis on clinical chemistry testing. ClinChem Lab Med. 2005;43(8):869-75.

5. Tolonen H, Ferrario M, Kuulasmaa K. Standardization of total cholesterol, measurement in population surveys pre-analytic sources of variation and their effect on the prevalence of hypercholesterolaemia. Eur J Cardiovasc Prev Rehabil. 2005;12:257-67.

6. Wallin 0. Preanalytical errors in hospitals: Implications for quality improvement of blood sample collection [dissertation]. Umea: Umea Univ. Sweden; 2008.

7. Donald S, Edward W, Doris M. Specimen collection and other pre-analytical variables. In: Carl AB, Edward
RA, David EB, editors. Tietz fundamentals of clinical chemistry. 6th ed. St Louis: Saunders; 2008 p. 42-62.

8. Hallworth M, Hyde K, Cumming A, Peake I. The future for clinical scientists in laboratory medicine. Clin Lab Haematol. 2002;24:197-204.

9. Plebani M, Carraro P. Mistakes in a stat laboratory: types and frequency. ClinChem 1997;43:1348-51.

10. Cole LA, Rinne KM, Shahabi S, Omrani A. False positive $\mathrm{Hcg}$ assay results leading to unnessary surgery and chemotherapy and needless occurrences of diabetes and coma. Clin Chem. 1999;45:313-4.

11. Lippi G, Guidi GC, Mattiuzzi C, Plebani M. Preanalytical variability: the dark side of the moon in laboratory testing. ClinChem Lab Med. 2006;44(4):358-65.

12. Karla J. Medical errors: impact on clinical laboratories and other critical areas. Clin Biochem. 2004;37:1052-62.

13. Lippi G, Fostini R, Guidi GC. Quality improvement in laboratory medicine: extra-analytical issues. Clin Lab Med 2008;28:285-94.

14. Broome TP, Holt JM. Venous stasis and forearm exercise during venipuncture as source of error in plasma electrolyte determinations. Canad Med Ass J. 1964:90:1105-7.

15. McMullan AD, Burns J, Paterson CR. Venepuncture for calcium assays: should we still avoid the tourniquet? Postgrad Med J 1990;66:547-8.

16. Junge $B$, Hoffmeister $H$, Feddersen HM, Rocker $L$. Standardization of obtaining blood samples: influence of tourniquet application on 33 constituents of blood and serum. Dtsch Med Wochenschr 1978;103:260-5.

17. Hill AB, Nahrwold ML, Noonan D, Northrop P. A comparison of methods of blood withdrawal and sample preparation for potassium measurements. Anesthesiology. 1980;53:60-3.

18. Renoe BW, McDonald JM, Ladenson JH. The effects of stasis with and without exercise on free calcium, variouscations, and related parameters. ClinChimActa 1980; 103:91-100. 
19. Oliveira LG, Lippi G,Salvagno GL, Montagnana M, Manguera CL, Sumita NM. New ways to deal with known preanalytical issues: use of transilluminator instead of tourniquet for easing vein access and eliminating stasis on clinical biochemistry. BiochemiaMedica. 2011;21(2):152-9.
20. Sonoli SS, Patil AB, Desai PB, Kodliwadmath MV, Prasad CV, Shivprasad. Tourniquet: Lacunae of preanalytics. Electron J Biomed. 2009;2:56-61.

\section{AUTHOR(S):}

1. DR. FARHEEN ASLAM, MBBS, DGO

Demonstrator Pathology/ 3rd year resident, Pathology Department,

Quaid-e-Azam Medical College, Bahawalpur. Pakistan.

2. DR. ASTHMA SHAUKAT

MBBS, MCPS, FCPS

Professor of Pathology,

Pathology Department, Quaid-e-Azam Medical College, Bahawalpur. Pakistan.

3. DR. ZAKIR ALI, MBBS

District Surveillance Coordinator

Executive District Office Health, Bahawalpur

Ahmedpur Road, Bahawalpur, Pakistan
4. Dr Tariq M Arain, MBBS, FCPS

Associate Professor Ophthalmology

Quaid-e-Azam Medical College, Bahawalpur

Correspondence Address:

Dr. Farheen Aslam (MBBS, DGO)

Demonstrator Pathology/ 3rd year resident,

Pathology Department,

Quaid-e-Azam Medical College, Bahawalpur. Pakistan.

House No: 8/D, Officers colony, Club road, Bahawalpur. Pakistan farheenaslam75@yahoo.com

Article received on: 22/02/2013 Accepted for Publication: 20/04/2013 Received after proof reading: 21/09/2013

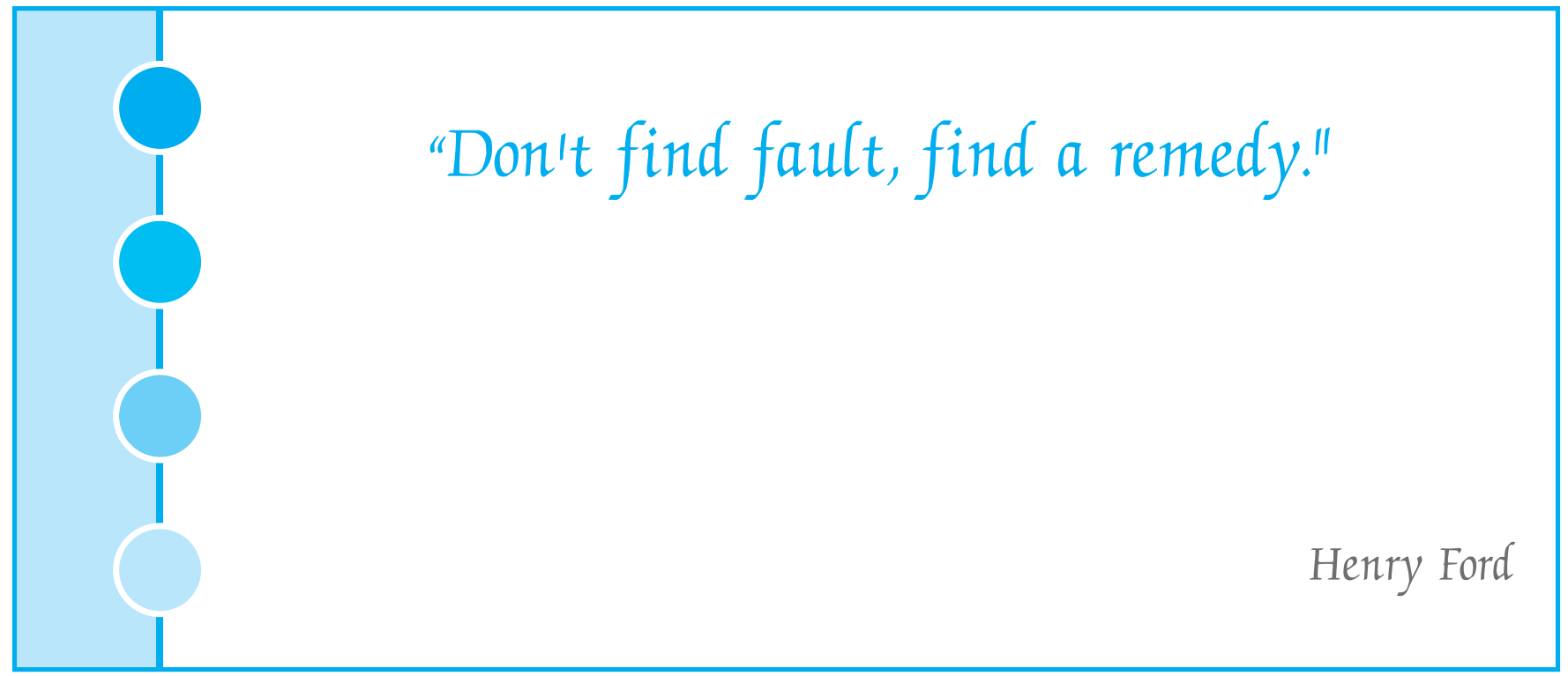

